\title{
Effects of Overhangs on the Performance of Electrochromic Windows
}

\author{
Aslihan Tavil* $\dagger$ and Eleanor S. Lee** \\ $* \uparrow$ Department of Architecture, Faculty of Architecture, Istanbul Technical University, Taşkışla, TR- \\ 34437, Istanbul, Turkey. Tel: +90 212293 1300/ 2356 (ext); Fax: +90 216567 4977; \\ E-mail: tavil@itu.edu.tr \\ ** Building Technologies Department, Environmental Energy Technologies Division, Lawrence \\ Berkeley National Laboratory, Mailstop 90-3111, 1 Cyclotron Road, Berkeley, CA 94720, USA. \\ E-mail: eslee@1bl.gov
}

Submitted 2 December 2005; accepted 20 July 2006

Running head: Overhangs and the Performance of Electrochromic Windows

\begin{abstract}
In this study, various facade designs with overhangs combined with electrochromic (EC) window control strategies were modeled for a typical commercial office building in a hot and cold climate using the DOE 2.1E building energy simulation program. EC windows were combined with overhangs since opaque overhangs provide protection from direct sun which EC windows are unable to do alone. The window wall was divided into an upper and lower aperture so that various combinations of overhang position and control strategies could be considered. The overhang was positioned either at the top of the upper window aperture or between the upper and lower apertures. Overhang depth was varied. EC control strategies were fully bleached at all times, modulated based on incident vertical solar radiation limits, or modulated to meet the design work plane illuminance with daylight. Annual total energy use (ATE), peak electric demand (PED), average daylight illuminance (DI), and daylight glare index (DGI) for south-facing private offices were computed and compared to determine which combinations of façade design and control strategies yielded the greatest energy efficiency, daylight amenity, and visual comfort.
\end{abstract}

Keywords: Electrochromic windows, Overhangs, Building simulation, Energy-efficiency, Visual comfort, Control algorithms

\section{Introduction}

Smart, switchable electrochromic (EC) windows promise to be the next major advance in emerging, energy-efficient window technologies because of their capability to change state from a clear to a colored tint without loss of view. This technology provides an opportunity to improve and optimize both energy-efficiency and comfort aspects of a building through dynamic control and integration with automated lighting controls designed to respond to daylight. Although EC windows can provide considerable energy savings and relatively stable daylight levels, they cannot block direct sun, which may result in unacceptable glare and reduced computer display visibility in office environments (Lee \& DiBartelomeo, 2002).

Over the past decade, many simulation studies have been conducted to estimate the energy-savings potential of EC windows for various climates. Simulation studies have also 
been used to identify control strategies that yielded the lowest energy use. The Lawrence Berkeley National Laboratory (LBNL) conducted numerous DOE-2 commercial building energy simulation studies in the mid-1990s (Sullivan, et al., 1997 and Sullivan, et al., 1994), concluding that significant annual total energy savings can be obtained compared to spectrally-selective low-emittance (low-e) windows in moderate to hot climates if large-area EC windows are controlled to maintain the interior illuminance set point and are combined with daylighting controls. In northern EU where commercial buildings are often heatingdominated and natural or passive cooling is encouraged, researchers have investigated alternate strategies with and without daylighting controls where the EC is switched to provide passive heating during the winter and to reduce cooling requirements and overheating during the summer. Karlsson (Karlsson, 2001) quantified heating and cooling annual energy savings for EC windows controlled by incident vertical solar radiation limits $\left(50-300 \mathrm{~W} / \mathrm{m}^{2}\right)$ in combination with occupancy-controlled lighting and ventilation systems and a heat recovery mode regulated by interior temperatures. This mode of control yielded small savings in the northern Stockholm climate and slightly greater savings in the warmer climates of Denver and Miami given the moderate window-to-wall ratio (WWR=0.30). Gugliermetti and Bisegna (Gugliermetti \& Bisegna, 2003) conducted a parametric study to identify optimum incident solar radiation limits that would yield the least total primary energy. A second set of simulations was conducted to address discomfort glare due to bright sky luminance then compared to these optimal savings. For these simulations, the daylight glare index was related to incident vertical solar radiation levels, then these limits were used to switch the EC windows for visual comfort. Total primary energy use was increased by a small margin (4$10 \%)$ on the east, south, and west facades and significantly $(19 \%)$ on the north façade with the visual comfort strategy compared to the best incident solar radiation strategies. These results were given for a moderate sized window $(W W R=0.33$ ) in a typical office for three climates in Italy. The electric lights were dimmed in response to daylight with photoelectric controls. When the space was unoccupied, the EC was bleached and the lights were turned off.

When EC windows are fully colored in order to control direct sun and glare, there are adverse effects on daylight levels, lighting energy savings, and room brightness (Sullivan, Rubin \& Selkowitz, 1997). To satisfy visual comfort requirements, EC windows may require interior or exterior shading devices to block direct sun. Fenestration elements such as overhangs combined with EC control strategies may enable one to achieve greater energyefficiency and visual comfort and it is likely that architects will wish to combine EC windows with attached exterior elements. The objective of this study is to determine the effect of various shading solutions of different overhang placements and depths on moderate and large area EC windows having various control algorithms in a cold (Chicago) and hot climate (Houston). Moreover, this study provides some indication of how best to control EC windows given typical architectural solutions and the level of performance that is likely to result.

\section{Methodology}

\section{Simulation Software}

A parametric study was conducted using the DOE-2.1E building energy simulation program (Winkelmann, et al., 1993) to generate relative performance data. DOE 2.1E is a comprehensive and general purpose thermal analysis program designed to explore the energy behavior of buildings and their associated HVAC systems. The program performs hourly thermal load and daylighting calculations based on the physical description of the building and ambient weather conditions. 


\section{Description of the Prototype Office Building}

The study involved the simulation of a $4459 \mathrm{~m}^{2}$ commercial office building prototype originally developed by LBNL (Carmody, et al., 2004). The prototype was a hypothetical building with reasonable parameters of size, envelope construction, HVAC system type, operating schedules, etc. based on the mean prevailing condition among statistical samples and engineering judgment. The three-storey prototype consisted of ground, intermediate and rooftop floors. Each floor has four $139 \mathrm{~m}^{2}$ perimeter zones, each consisting of ten $3.04 \mathrm{~m}$ wide, $4.6 \mathrm{~m}$ deep, $2.75 \mathrm{~m}$ high private offices and a $929 \mathrm{~m}^{2}$ core zone. The building was oriented true north with each façade facing one of the four cardinal directions. Light-weight construction was used. Insulation values for the envelope were obtained from the ASHRAE Standard 90.1-1999. Peak occupant density was $25.5 \mathrm{~m}^{2}$ per person in the perimeter zones. Peak equipment loads were $8.1 \mathrm{~W} / \mathrm{m}^{2}$. Schedules corresponded to data from ASHRAE 90.11989 and other field studies. Simulations were made for a cooling-dominated location (Houston) and a heating-dominated location (Chicago). Climate data are given in Table 1.

Recessed fluorescent lighting was modeled with a lighting power density (LPD) of 12.9 $\mathrm{W} / \mathrm{m}^{2}$. Full LPD levels were modified by the occupancy schedule (e.g., at 8:00, 30\% of full LPD was on, at 12:00, 90\% of full LPD was on) in combination with daylighting controls. Heat was apportioned to the interior space $(60 \%)$ and to the unconditioned plenum $(40 \%)$. With daylighting controls, the perimeter zone electric lights were dimmed linearly to provide 538 lux at the work plane located $3.0 \mathrm{~m}$ from the window wall, centred on the window and at a height of $0.76 \mathrm{~m}$ above the floor. The electronic dimmable ballasts were modeled with a linear power consumption range of 100-33\% with 100-10\% light output. Surface reflectances were 0.7 for ceilings, 0.5 for walls, and 0.2 for floors.

Five variable-air-volume systems with economizers were employed: one for each perimeter zone and one for the core zone (all three floors per orientation or core zone were controlled by one system). The heating thermostat set point was $21.1^{\circ} \mathrm{C}$ during occupied hours with a night setback temperature of $12.8^{\circ} \mathrm{C}$. Heating was provided by a gas boiler and cooling was provided by a hermetic centrifugal chiller and cooling tower.

\section{Window Systems}

Flush-mounted, non-operable EC windows were modeled in the exterior wall of each perimeter zone office. Two window sizes were modeled with a total window-to exterior-wallarea ratio (WWR) of 0.30 (moderate punched window opening) and 0.60 (nearly floor-toceiling glass). The exterior wall had a height of $3.66 \mathrm{~m}$. The window area includes the frame. The window head height was set flush with the ceiling at $2.75 \mathrm{~m}$ (typical ceiling height in the US). Based on prior research that identified the energy-efficiency drawbacks of controlling an EC façade as a single zone (Lee, et al., 2006), the EC façade was split into an upper and lower aperture, each controlled independently. The height of the upper aperture was kept constant at $61 \mathrm{~cm}$ for both window sizes. The window positions and sizes are given in Figure 1 and Table 2.

The exterior $6 \mathrm{~mm}$ glazing layer had a $\mathrm{WO}_{3} \mathrm{EC}$ coating on the inboard surface. Its emittance was 0.84 on the exterior and 0.15 on the interior surface. The EC glazing was combined with a $6 \mathrm{~mm}$ interior clear glazing layer to form an insulating glazing unit with a $12.7 \mathrm{~mm}$ wide air gap (a dual-pane construction is typically required for EC coatings). All windows were modeled with a $12.7 \mathrm{~mm}$ aluminum spacer, air gas fill, and thermally-broken 
aluminum frame $\left(\mathrm{U}_{\text {frame }}=5.67 \mathrm{~W} / \mathrm{m}^{2} \mathrm{~K}\right)$. EC window properties are given in Table 3. The EC was not combined with an interior shade.

The EC window was switched based on daylight or total incident vertical solar radiation levels. The upper aperture was controlled independently from the lower aperture. The window was modeled to switch linearly over a continuous (infinite) range between bleached and colored states. For the daylight control strategy, the EC transmittance was modulated so as to provide 538 lux (equals $50 \mathrm{fc}$ standard practice in US) at $3.05 \mathrm{~m}$ from the window wall, centered widthwise on the window, and at a work plane height of $0.76 \mathrm{~m}$ every hour during daylight hours. If there was insufficient daylight, the window was switched to fully bleached. If there was too much daylight, the window was switched to fully colored. For the switching strategies based on irradiance, the EC was modulated between two threshold values established by a prior simulation study (Sullivan, et al., 1994). The EC was bleached when the irradiance was less than or equal to $63 \mathrm{~W} / \mathrm{m}^{2}$, fully colored when the irradiance was greater than or equal to 95 or $315 \mathrm{~W} / \mathrm{m}^{2}$, and partially colored when the irradiance level was between the two threshold values. The combinations of EC switching strategies for the upper and lower apertures are given in Table 4.

\section{Exterior Shading}

Overhangs were modeled as opaque, non-reflective surfaces. These obstructions blocked diffuse light from the sky and direct sun but reflected no light from the ground or its upper surface (no effect on interior daylighting). Four overhang depths were modeled: 0.85, 1.0, 1.3 , or $1.5 \mathrm{~m}$. The width of the overhang was made the same width as the office module: 3.05 $\mathrm{m}$. The height of the overhang was set so that its lower surface was flush with the top of either the lower or upper framed window opening, hereafter referred to as the "betweenwindow" or "top-of-window" overhang position.

\section{Parametric Study}

A parametric study was conducted that compares the performance of various combinations of EC façade designs and control algorithms in a hot climate (Houston, Texas) and a cold climate (Chicago, Illinois). The base case is identical to the test case except it has no overhang. The percentage of savings in annual total energy use (ATE) and peak electric demand (PED) for the south zone of three-storey commercial building was computed.

Perimeter zone annual cooling electricity use was determined using system-level extraction loads converted to plant-level electricity use with a fixed coefficient of performance (COP) of 3.0. This was added to the perimeter zone annual electricity use data (includes lighting, convenience outlets, and supply and return fans for heating, heating and cooling, and float periods) to arrive at total annual electricity use. Peak electric demand (PED) was determined in a similar manner. Demand data are given for the peak condition that occurs in each perimeter zone and are non-coincident with the whole building's peak condition.

Perimeter zone annual heating energy use was determined using system-level extraction loads converted to plant-level energy use with a fixed heating efficiency factor (HEF) of 0.8. Fan electric energy use for hours when only heating is required was not added to this quantity to enable total energy performance comparisons based on fuel type.

Total primary annual energy use (heating + electricity) was then computed using a site-tosource efficiency of 3.0 for electricity and 1.0 for natural gas. The site-to-source efficiency indicates the generating efficiency of the fuel or utility (including transmission and distribution losses) prior to its use in the simulated building. 
The average annual daylight illuminance (DI) for the south zone is given at $3.05 \mathrm{~m}$ from the window wall, centered on the window and at a workplane height of $75 \mathrm{~cm}$. The average annual daylight glare index (DGI) is given at a typical occupant's view position $1.5 \mathrm{~m}$ from the window wall, centered on the window, looking at the east side wall, at a height of $1.21 \mathrm{~m}$ above the floor. Optimum solutions are identified by analyzing these performance data as a function of window size, EC control algorithm, and overhang placement and depth for heating- and cooling-dominated climates.

\section{Annual Total Energy Use}

The percentage reductions in Anjual Energy Use (ATE) for large- and moderate-area EC windows with overhangs of various depths versus no-overhang case are given for Houston and Chicago in Figure 2-a, b, c, d. When an overhang is combined with an EC window, annual cooling energy is decreased for all overhang configurations while annual lighting energy use varies depending on the overhang design and switching control algorithms for both window sizes. The simulation results indicate that several EC switching control strategies provide greater energy-efficiency than the EC window alone, depending on the placement of the overhang, particularly for large-area windows. Up to $14 \%$ and $10 \%$ savings can be achieved depending on the overhang depth and control algorithm in Chicago and Houston, respectively, if the window area is large.

The placement of the overhang affects the effectiveness of the control algorithm. The percentage of savings is greater for some control algorithms with the between-windows overhang case because the upper aperture admits daylight, which can then decrease lighting energy use. Maximum savings for all overhang designs were attained by controlling the upper and lower EC windows based on incident total solar radiation (D) for large and moderate area windows in both climates. Savings were $9 \%$ and $13 \%$ for large-area EC windows in Houston and Chicago, respectively, while the savings were approximately $7 \%$ for moderate-area EC windows in both climates.

In Chicago, control algorithms D, E and F yielded better performance for the betweenwindow overhang case. In Houston, algorithms C, D, and E yielded almost the same performance for either overhang locations while algorithm $\mathrm{F}$, which was designed to minimize glare in the lower aperture and bring daylight into through the upper aperture, yielded better performance for the between-window overhang case. With this case, algorithm F maintained the lower aperture at or near the fully colored state for most hours in the year while the upper aperture, which was modulated for daylight, provided daylight to offset lighting energy use requirements. Further studies can be conducted to optimize the area of the upper aperture for algorithm F: this aperture may be too small to provide the required daylight illuminance (see below), which may increase lighting energy use.

Deeper overhangs attached either at the top or between the EC apertures provided virtually no savings for a moderate-area window and small savings ( $\sim \%$ maximum) for a large-area window in Chicago. The same can be said for Houston, where a change in depth from $85 \mathrm{~cm}$ to $150 \mathrm{~cm}$ produced a maximum reduction in energy use of only $\sim 3 \%$.

\section{Peak Electric Demand}

The percentage reductions in Peak Electric Demand (PED) provided by EC windows combined with overhangs of various depths and locations versus no-overhang options are presented in Figure 3-a, b, c, d.

Use of an overhang significantly decreases PED by reducing incident solar radiation on the façade, thus lowering the cooling load. This is particularly true for large-area windows in 
hotter geographic locations. Greater savings can be achieved by attaching the overhang at the top of the window for the most EC configurations. Greater savings are achieved with increased overhang depth, particularly for large-area windows. The greatest PED reductions are achieved again with control algorithm $\mathrm{D}$ for all window designs, with algorithm $\mathrm{B}$ being a close contender in Houston for the top of window overhang case.

\section{Annual Daylight Illuminance and Daylight Glare Index}

From the energy-efficiency perspective, daylight offsets the need for electric lighting by providing adequate levels of illuminance in a space. More daylight does not necessarily equate to better lighting conditions. It is a matter of balancing daylight admission with glare control. Average annual work plane daylight illuminance (DI) is given as a function of various EC control algorithms and window designs in Figure 4-a, b, c, d. All data are given as an average of the year, where the year is defined by all hours when the sun is above the horizon to show relative daylight efficiency between the cases (if defined by working hours, then the average would include nighttime hours in the winter).

For most of these window designs and EC control algorithms, DI levels did not exceed the design level of 538 lux for most configurations in either climate. One cannot conclude that this metric is an indicator of gloom; alternate performance metrics would need to be calculated to assess interior brightness. There were several exceptions. With no overhang and WWR=0.6, DI levels were between 1300-1600 lux for this south-facing window in Chicago (latitude $=42^{\circ}$ ). With the between-window overhang position, DI was also between 1300-1600 lux for control algorithms A and B for all overhang depths. Direct sun from low winter sun angles was admitted through the fully-bleached EC upper aperture and increased average DI in south facing room in higher latitudes. In Houston, DI values were increased for control algorithms B, E, and F for the between-window overhang position. For example, DI values for control algorithm $\mathrm{F}$ was 89-122 lux for the top-of-window overhang position and 260-263 lux for the between-window overhang position given a moderate-area window. As mentioned earlier, the lower EC was controlled to near or at the fully colored state, so the upper aperture was controlled to at or near the clear state for most of the year in order to reach the daylight illuminance design level.

The average annual daylight glare index (DGI) for different EC window configurations is given in Figure 5-a, b, c, d. This DGI is an approximate measure of visual discomfort one feels from a large-area daylight source within one's peripheral view. A DGI value of 10 is the threshold between "just imperceptible" and "just acceptable" discomfort glare. In conventional designs, glare control often conflicts with the control objectives for energy efficiency since daylight illuminance are often diminished significantly in order to achieve a glare-free environment. With the proper façade design and control algorithm, it is possible to achieve both objectives. For example, control strategy F yields the lowest annual DGI for all cases because the lower EC aperture is most often in a dark tinted state throughout the year thus reducing the luminance of the large-area glare source. If the between-window overhang position is selected, the ATE performance is nearly comparable to the optimal ATE EC control: algorithm D. Algorithm D has a less stringent control of the lower aperture and therefore has a significantly greater DGI value than algorithm $\mathrm{F}$ with only a $2 \%$ increase in percentage ATE reduction.

\section{Conclusion}

Field studies, lighting studies using ray-tracing simulation tools, and human subjects studies conducted with EC windows indicate that the EC windows must be combined with 
either interior or exterior shading to control direct sun. Even if the EC were to achieve a visible transmittance of 0.001 in the colored state, the orb of the sun at over a billion $\mathrm{cd} / \mathrm{m}^{2}$ as it approaches the meridian is still a decisive glare source. Therefore, performance indices such as DGI and other visual comfort indicators must be considered with equal weight when evaluating the energy-savings and market potential of emerging technologies such as electrochromic windows. If the criteria are to maximize energy use savings while minimizing discomfort glare, then overhangs combined with the proper control algorithm can increase the performance of EC windows while mitigating the effects of direct sun:

1) For cold climates like Chicago with EC window designs of moderate area, betweenwindow overhang position with control algorithm $\mathrm{D}$ best meets this criteria, but strategies $\mathrm{E}$ and $\mathrm{F}$ yield almost equitable ATE reductions with slightly lower glare. Overhang depth was of no consequence. ATE reductions were 6-9\% with DGI levels of 1-3. PED reductions were 10-17\%. DI levels were 200-400 lux.

2) For cold climates with large-area EC windows, between-window overhang position with control algorithm F meets the criteria. Glare was controlled through the lower aperture and the upper aperture provided sufficient daylight to offset lighting energy use requirements. The overhang provided additional protection from direct solar heat gains. Overhang depth was of no consequence. ATE reductions were $10-11 \%$ with DGI levels of 4 . PED reductions were $11-14 \%$. DI levels were 400 lux.

3) For hot climates like Houston with moderate-area EC windows, control algorithm D best meets the criteria with either overhang position. Increasing overhang depth had minor impact on ATE but a greater impact on PED. ATE reductions were 6-9\% with DGI levels of 2-4. PED reductions were 15-19\%. DI levels were 200-300 lux.

4) For hot climates with large-area EC windows, differences in DGI drive the selection of the best case. The between-window overhang position with control algorithm $\mathrm{F}$ best meets the criteria. Increasing overhang depth has some impact on ATE but a greater impact on PED. ATE reductions were 6-8\% with DGI levels of 5. PED reductions were $11-18 \%$. DI levels were 400 lux.

Further work is required to gain a better understanding of how best to optimize the energy and comfort potential of EC windows. Combining EC windows with light-redirecting, suncontrol systems hold even greater potential for achieving energy-efficiency and market acceptance.

\section{Acknowledgments}

This work was supported by the California Energy Commission through its Public Interest Energy Research Program, by the Assistant Secretary for Energy Efficiency and Renewable Energy, Office of Building Technology, State and Community Programs, Office of Building Research and Standards of the U.S. Department of Energy under Contract No. DE-AC0205CH11231, and by the Scientific and Research Council of Turkey (TUBITAK) through NATO-B2 Fellowship Program. We thank the editor and reviewers for taking the time to make a comprehensive review of this paper. 


\section{References}

Carmody, J., Selkowitz, S., Lee, E.S., Arasteh, D., \& Willmert, T. (2004). Window Systems for High Performance Buildings. New York: Norton.

Gugliermetti, F., \& Bisegna, F. (2003). Visual and energy management of electrochromic windows in Mediterranean climate. Building and Environment, 38, 479-492.

Karlsson, J. (2001). Control system and energy saving potential for switchable windows. In Proceedings of the Seventh International IBPSA Conference, Rio de Janeiro, Brazil, August, pp. 199-206.

Lee, E.S., \& DiBartolomeo, D.L. (2002). Application issues for large-area electrochromic windows in commercial buildings. Solar Energy Materials \& Solar Cells, 71, 465-491.

Lee, E.S., DiBartolomeo, D.L., Klems, J.H., Yazdanian, M., \& Selkowitz, S.E. (2006).

Monitored energy performance of electrochromic windows controlled for daylight and visual comfort. In ASHRAE Transactions.

http://windows.lbl.gov/comm perf/Electrochromic/

Winkelmann, F.C., Birdsall, B.E., Buhl, W.F., Ellington, K.L., \& Erdem, A.E., (1993). DOE2.1E Supplement, LBNL-34947. Washington, DC: Unpublished report, US Department of Energy.

Sullivan, R., Lee, E.S., Papamichael, K., Rubin, M., \& Selkowitz, S. (1994). Effect of switching control strategies on the energy performance of electrochromic windows. In Proceedings of the SPIE International Symposium on Optical Materials Technology for Energy Efficiency and Solar Energy Conversion XIII, Freiburg, Germany, 18-22 April.

Sullivan, R., Rubin, M., \& Selkowitz, S. (1997). Energy performance analysis of prototype electrochromic windows. ASHRAE Transactions, 103(2), xxx-yyy. 


\begin{tabular}{lrrrrrr}
\hline & HDD & CDD & $\begin{array}{r}\text { Latitude } \\
\left({ }^{\circ}\right)\end{array}$ & $\begin{array}{r}\text { Longitude } \\
\left({ }^{\circ}\right)\end{array}$ & $\begin{array}{r}\text { Elevation } \\
(\mathrm{m})\end{array}$ & $\begin{array}{r}\text { Hrs } \\
\text { Sun up }\end{array}$ \\
\hline Chicago O'Hare & 6536 & 2941 & 41.98 & 87.90 & 205 & 4757 \\
Houston Hobby & 1599 & 6876 & 29.97 & 95.35 & 29 & 4755 \\
\hline
\end{tabular}

Notes: HDD: heating degree days base $18.3^{\circ} \mathrm{C}$, CDD: cooling degree days $10^{\circ} \mathrm{C}$, HDT: heating design temperature (99.6\%); CDT: cooling design temperature (1.0\%); Hrs Sun Up: number of hours the sun is above the horizon.

Table 2

Window dimensions

\begin{tabular}{lrrrrrrr}
\hline $\begin{array}{l}\text { Window- } \\
\text { to-wall }\end{array}$ & $\begin{array}{r}\text { Exterior } \\
\text { wall area }\end{array}$ & \multicolumn{3}{c}{ Lower window } & \multicolumn{3}{c}{ Upper window } \\
ratio & $(\mathrm{m} 2)$ & $(\mathrm{m})$ & $(\mathrm{m})$ & & $\begin{array}{r}\text { hidth } \\
\text { width }\end{array}$ & $\begin{array}{r}\text { height } \\
\text { height }\end{array}$ & WWR2 \\
\hline 0.3 & 11.15 & 1.83 & 1.22 & 0.20 & 1.83 & 0.61 & 0.10 \\
0.6 & 11.15 & 3.05 & 1.58 & 0.43 & 3.05 & 0.61 & 0.17 \\
\hline
\end{tabular}

Note: Dimensions and window-to-exterior-wall ratio (WWR) includes frame.

Table 3

EC window properties

\begin{tabular}{|c|c|c|c|c|c|c|c|c|c|}
\hline Outer layer & $\begin{array}{l}\text { Inner } \\
\text { layer }\end{array}$ & $\begin{array}{c}\mathrm{U} \\
(\mathrm{W} / \mathrm{m} 2 \mathrm{~K} \\
{ }_{\text {overall }}\end{array}$ & $\begin{array}{c}\mathrm{U} \\
\mathrm{COG}\end{array}$ & $\begin{array}{l}\text { SHGC } \\
\text { overall }\end{array}$ & $\begin{array}{c}\text { SHGC } \\
\text { COG }\end{array}$ & $\begin{array}{c}\mathrm{Tv} \\
\text { overall }\end{array}$ & $\begin{array}{c}\mathrm{TV} \\
\mathrm{COG}\end{array}$ & CRI & $\begin{array}{c}\text { Spac } \\
\text { ers }\end{array}$ \\
\hline $\begin{array}{l}\text { Bleached } \\
\text { EC }\end{array}$ & Clear & 2.87 & 1.87 & 0.37 & 0.42 & 0.45 & 0.56 & 92.7 & Alum \\
\hline Colored EC & Clear & 2.87 & 1.87 & 0.10 & 0.09 & 0.02 & 0.02 & 52.3 & Alum \\
\hline
\end{tabular}

Notes: COG: Center-of-glass; CRI: Color rendering index; EC: electrochromic glazing; SHGC: solar heat gain coefficient; Alum: aluminum. U-values are given for ASHRAE winter conditions. Overall U-values are given for a window whose overall dimensions including a $76 \mathrm{~mm}$ wide frame are $1.22 \times 1.8 \mathrm{~m}$. SHGC computed for ASHRAE summer conditions. All properties were determined using WINDOW4.1 and Optics5 (v.2.0.2). 
Table 4

Electrochromic window control strategies

\begin{tabular}{lll}
\hline & EC1 - lower aperture & EC2 - upper aperture \\
& Control strategy & Control strategy \\
\hline A & Daylight & None: always clear \\
B & Iv $=63-315 \mathrm{~W} / \mathrm{m} 2$ & None: always clear \\
C & Daylight & Daylight \\
D & Iv $=63-315 \mathrm{~W} / \mathrm{m} 2$ & Iv=63-315 W/m2 \\
E & Iv $=63-315 \mathrm{~W} / \mathrm{m} 2$ & Daylight \\
F & Iv $=63-95 \mathrm{~W} / \mathrm{m} 2$ & Daylight \\
\hline
\end{tabular}

Note: Daylight: EC modulated to meet design work plane illuminance of 538 lux; Iv is total incident vertical solar radiation on south-facing window.

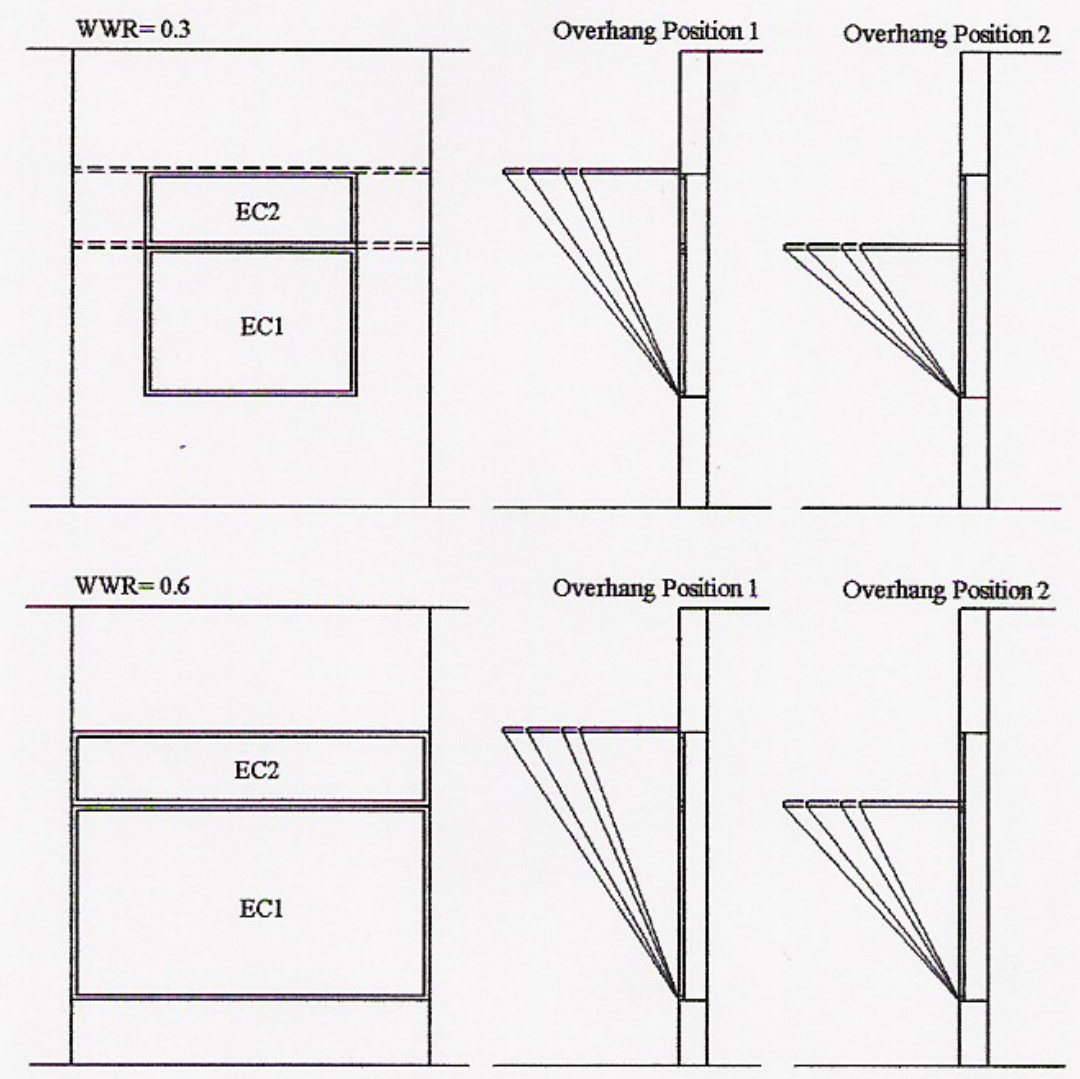

Figure 1: Window system configurations. 

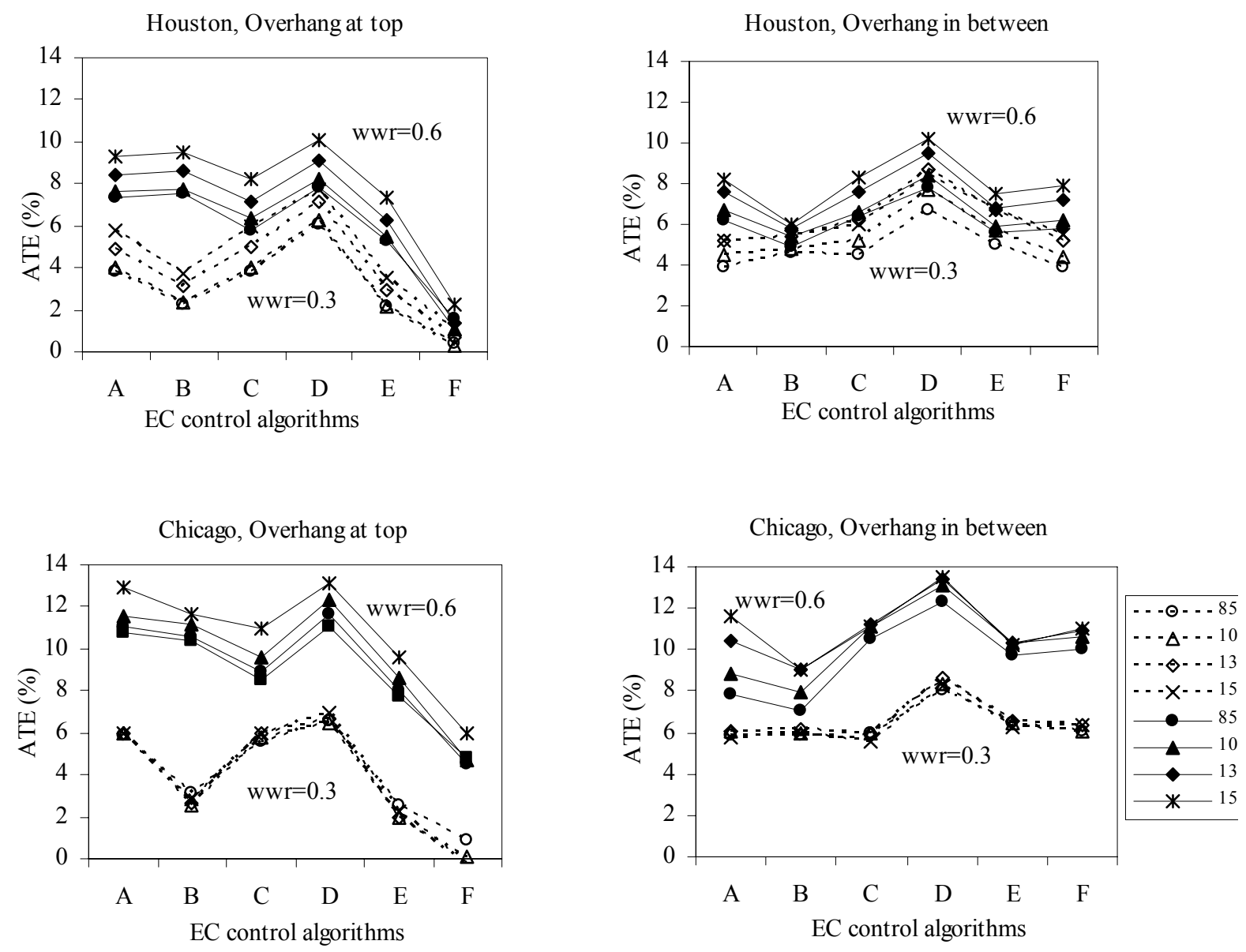

Figure 2: Percentage reduction in ATE when various depths of overhangs are combined with large- $(\mathrm{WWR}=0.6)$ and moderate-area $(\mathrm{WWR}=0.3) \mathrm{EC}$ windows having various control algorithms versus the same configuration without an overhang. 

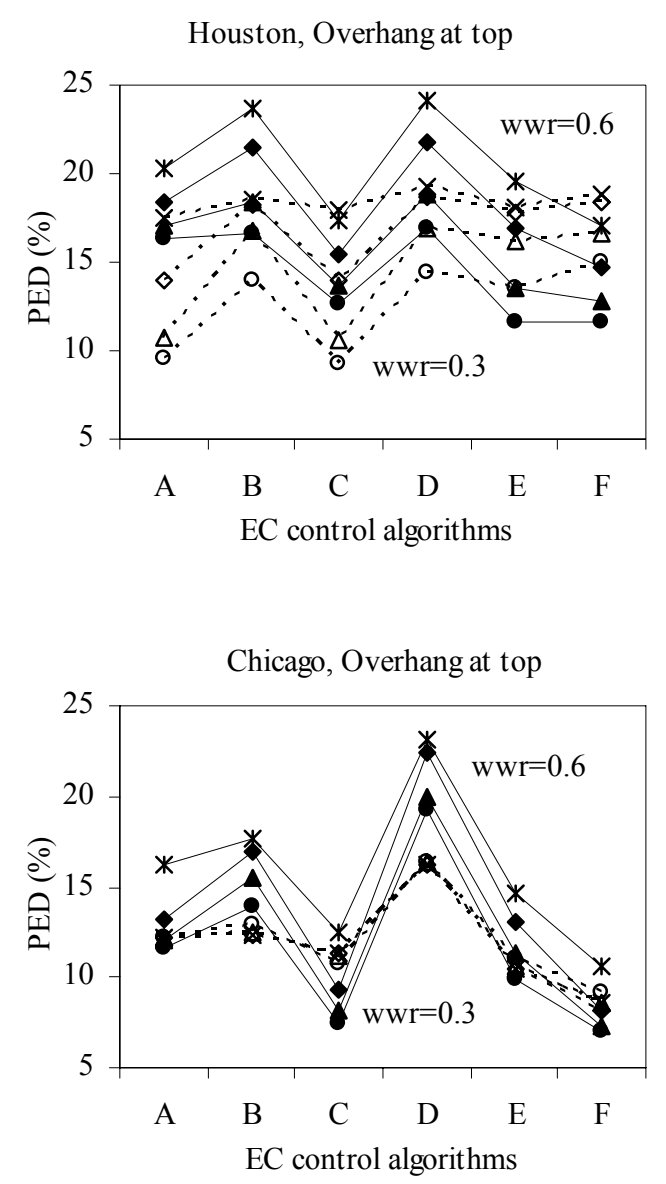
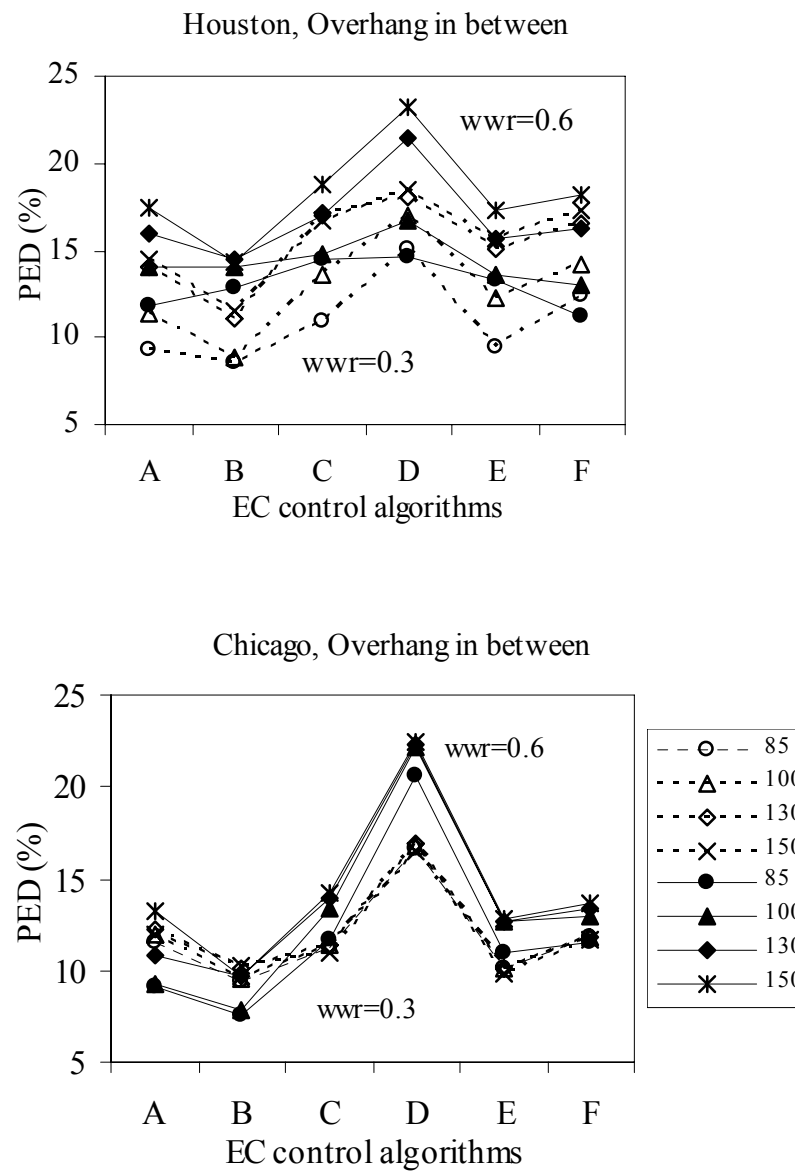

Figure 3: The rate of reduction in PED when various depths of overhangs are combined with large- $(\mathrm{WWR}=0.6)$ and moderate-area $(\mathrm{WWR}=0.3) \mathrm{EC}$ windows having various control algorithms versus the same configuration without an overhang. 

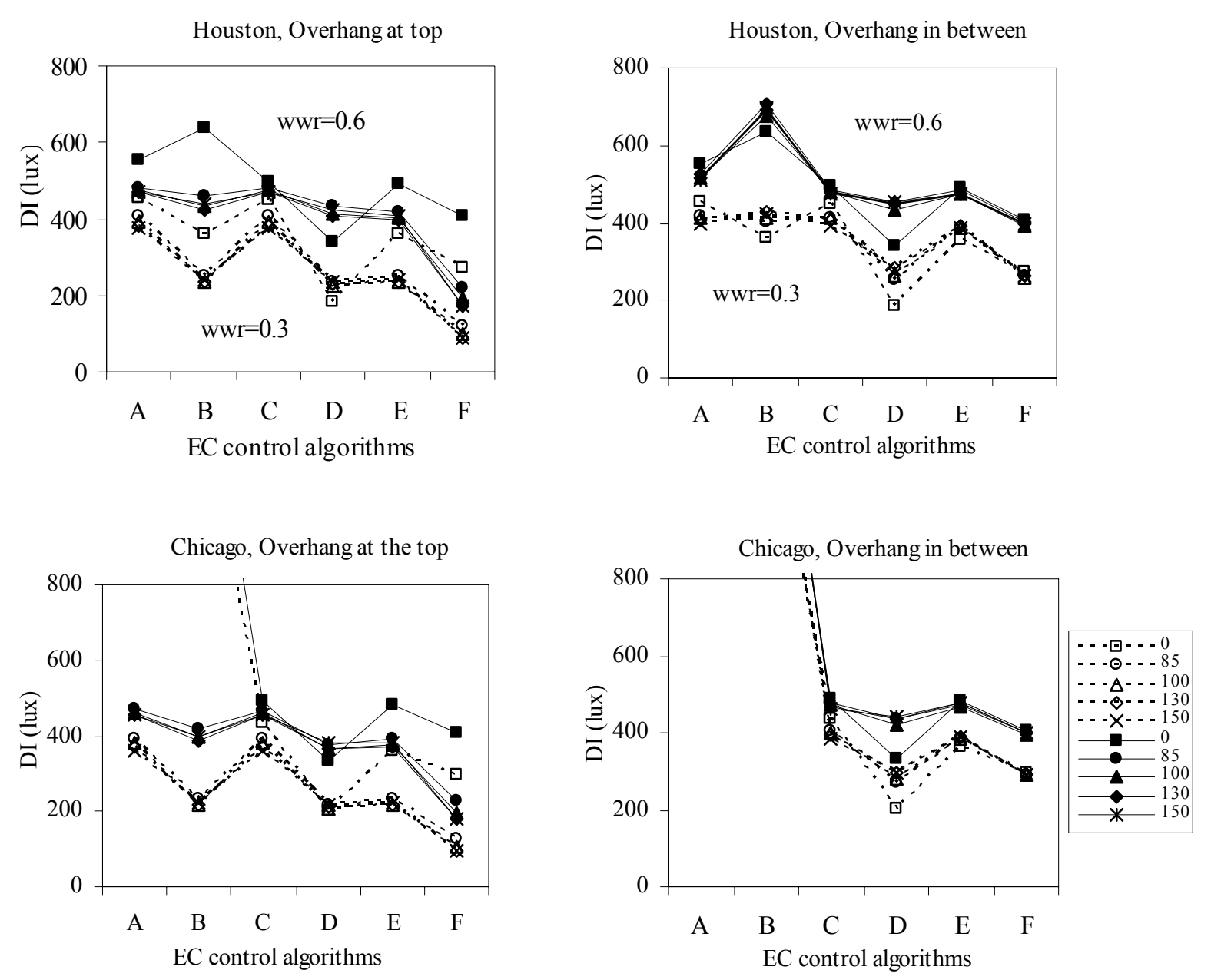

Figure 4: Average annual daylight illuminance (DI) at $3.05 \mathrm{~m}$ from the window, centered on the window, and at a work plane height of $75 \mathrm{~cm}$. 

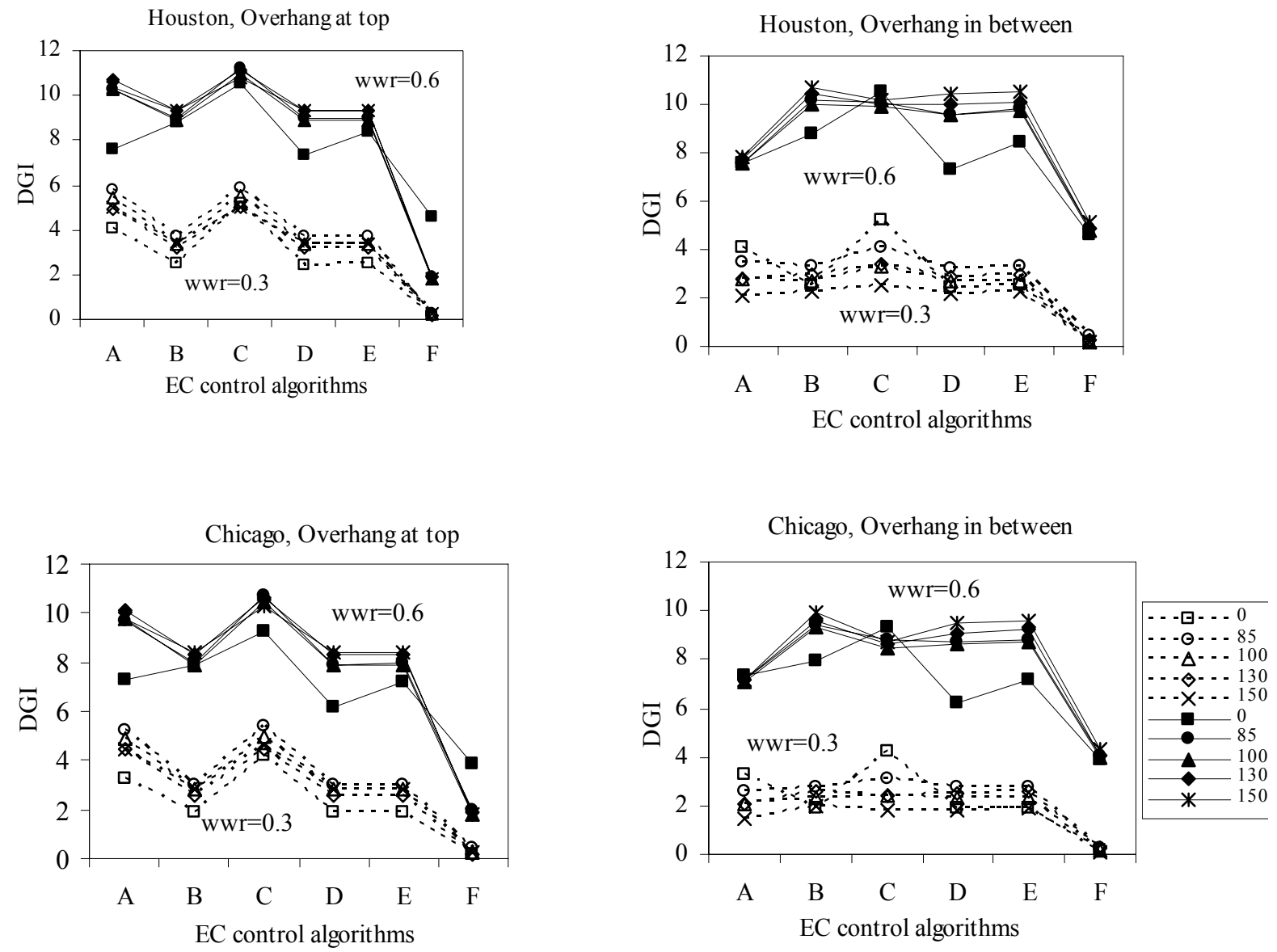

Figure 5: Average annual daylight glare index (DGI) for a view $1.5 \mathrm{~m}$ from the window looking at the side wall. 